\title{
Las medicinas tradicionales en la encrucijada intercultural
}

\section{Traditional medicines at an intercultural crossroads}

\author{
Carmen Beatriz Loza \\ Directora de investigación, Instituto Boliviano de Medicina Tradicional Kallawaya. \\ cbloza@gmail.com
}

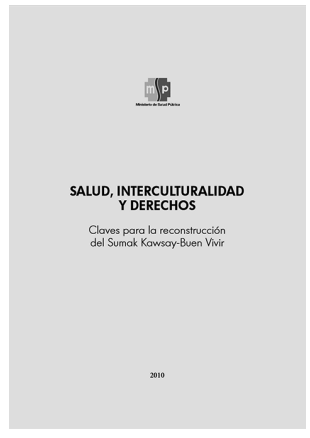

FERNÁNDEZ JUÁREZ, Gerardo (Ed.). Salud, interculturalidady derechos: claves para la reconstrucción del Sumak Kawsay-Buen Vivir. Quito: Ministerio de Salud Pública. 2010 238p.
$\mathrm{E}$ sta obra colectiva, compilada por el antropólogo español Gerardo Fernández Juárez (Universidad Castilla-La Mancha), es fruto de un seminario-taller interdisciplinario, celebrado en Quito del $10 \mathrm{al}$ 13 de noviembre del 2009. Agrupa diferentes maneras de entender la interculturalidad y la salud materna desde la antropología y la biomedicina. La reseña de esta obra tiene un doble propósito. Por un lado, presentar el contenido en sus grandes líneas, resaltando el discurso oficial de la interculturalidad en salud en la subregión andina con énfasis en el Ecuador, y por el otro, evidenciar divergencias de criterios acerca de su implementación.

La intención de los autores es presentar los avances y desafíos en la incorporación de los enfoques de derechos humanos, interculturalidad y género en las políticas y modelos de atención en salud materna. A esa exigencia se suma otra, que de alguna manera resume y potencia las anteriores: analizar las cuestiones pendientes y profundizar la discusión crítica entre ministros, operadores y decidores de las políticas acerca del tema de la Declaración de Quito (13 de noviembre de 2009). Se pretende, con los Objetivos de Desarrollo del Milenio, reducir las tres cuartas partes de la mortalidad materna (considerando el período 1999-2015). El hilo rojo que recorre los 35 textos es la implementación de la interculturalidad y el uso político desde el Estado en el ámbito de la salud. En cada texto se puntualiza y redefine la interculturalidad de manera recurrente, debido al carácter escurridizo y opaco de este concepto. La primera parte se centra en los derechos humanos, salud intercultural y en "el Buen Vivir" (un concepto filosófico-andino, retomado por los gobiernos de Rafael Correa y Evo Morales, como principio rector de sus acciones políticas para el bienestar de la población). La segunda parte examina la interculturalidad, género y salud, mientras la tercera parte refiere a la pertinencia cultural de los servicios de salud reproductiva: normas, regulaciones y gestión de servicios. Todo ese conjunto temático tiene como destinatario potencial a los decidores de las políticas públicas en salud en la subregión 
andina, pues muchas de las narraciones provienen de los responsables de programas en actual aplicación. Además algunos de los autores han dirigido la sistematización de las siete mesas que generaron propuestas y recomendaciones específicas acerca de la normativa, formación de recursos, gestión de servicios entre otros. La obra puede ser útil para los investigadores en ciencias sociales y politólogos interesados en las formas que asume la interculturalidad como política de Estado. Las narrativas de estos decidores y estudiosos, próximos a la cooperación internacional y las instituciones de salud estatales, son una oportunidad única para escudriñar en su pensamiento. La obra ofrece los antecedentes académicos del 68\% de los autores dejando a un $32 \%$ de lado de un total de 31 participantes, sin ofrecer mayores explicaciones. Utiliza como complemento un anexo de 21 fotografías de los participantes.

La política intercultural en salud, particularmente centrada en el cumplimiento de la Reforma Constitucional en Ecuador y Bolivia, ocupa la primera parte. Las contribuciones son de diversos autores: de Gerardo Fernández Juárez, Luís Fernando Calderón, Luis Enrique "Katsa" Cachiguanco, Luis Maldonado Ruiz, Amilcar Castañeda, José Solá y Fernando Ortega Pérez. Una apretada síntesis de Gerardo Fernández Juárez presenta las paradojas de la salud intercultural a tiempo de realizar un balance crítico de su implementación estatizada. Por otro lado, Luís Fernando Calderón da cuenta de la forma cómo la administración del presidente Rafael Correa está trabajando en el campo de la salud. Este autor, a partir de una visión dicotómica, amplifica los defectos y males que aquejaron la política de salud del Ecuador desde 1985 hasta 2007 y ensalza aquellas en vigencia. Para ello señala que el modelo biomédico occidental habría sido el único mientras que actualmente se adopta a las medicinas tradicionales y las alternativas. Menciona 17 experiencias locales para el fortalecimiento de las redes biomédicas con miras a la implementación del Modelo de Salud Familiar y Comunitario. Calderón silencia el funcionamiento de las experiencias hospitalarias locales, sus resultados y problemas, dejando abierta la exposición técnica a sus colegas. Ensalza la acreditación de los terapeutas tradicionales y vislumbra que en el futuro se trabajará en "procesos de validación de las terapias complementarias y alternativas para evitar la mala práctica y la superchería en su ejecución" (p.59). En su artículo no existen datos específicos acerca del destino exacto de las medidas tradicionales indígenas en todo el proceso de la instauración de la salud intercultural.

La institucionalización de los terapeutas tradicionales y su empoderamiento dentro de los hospitales es defendida por la mayoría de los autores. Empero, el médico salubrista ecuatoriano, José Sola, la cuestiona frontalmente al señalar que:

La presencia de los agentes tradicionales en las unidades públicas de salud, les lleva a un proceso de institucionalización con su consecuente integración al sistema formal y la subordinación a un conjunto de normativas y jerarquías que obscurecen su propio referente filosófico (atender enfermos y no tratar enfermedades) y que desnaturaliza su autonomía, pero sobre todo se resquebraja una práctica que es esencialmente comunitaria, con lo cual se anula su sentido de solidaridad, se debilitan las redes sociales de apoyo y se maltratan las formas locales de la reciprocidad (p.121).

Esta cita evidencia claramente que los sistemas médicos tradicionales están siendo cooptados y sub-alternizados. La prueba es que se da fe que en el altiplano boliviano de Patacamaya, en el 2009, los terapeutas tradicionales no recibían salario por sus servicios (p.218). 
La segunda parte muestra un diálogo entre interculturalidad y género. Cuenta con la participación de Lilia Rodríguez, Rocío Roser, Katherine Chalá, Irma Bautista, Gloria Lagos Roberto Campos, Margarita Sáez, Mario Tavera, Nancy Millán, Mónica Yaksic, Marcos Paz, Zulema Gambirazio, Daniel González, Jorge Hermida, Genny Fuentes, Steven Harvey, Juana María Freire, Miriam Cornejo y Jannine Crespo. Desde los distintos textos se abordan cuestiones tan diversas acerca de los avances realizados 15 años después de la Conferencia del Cairo (1994) resaltando la participación del Ecuador. Destaca por su esfuerzo de síntesis el artículo de Margarita Sáez, quien sintetiza brevemente los avances chilenos en la construcción de una estrategia para la pertinencia cultural en la organización y provisión de servicios de salud y la complementariedad de servicios médicos. Según la autora, a pesar de la política intercultural, "[el] modelo médico sigue siendo occidental y el proceso de cambio cultural es incipiente" en los 25 servicios de salud intercultural chilenos (p.231). La autora no sólo ofrece indicadores del éxito de la implementación de estas medidas sino también refle-xiones e interrogantes que cuestionan la asimetría de las relaciones entre sistemas médicos, una vez incorporada la interculturalidad. Según sus palabras, "[la] tendencia es 'integrar' [el parto] a un modelo oficial, que aunque 'abierto' y respetuoso sigue siendo dominante" (p.230).

La tercera parte, la más pequeña, cuenta apenas con dos contribuciones: de Ariuma Kowii, sobre sexualidad en adolescentes y jóvenes kichwa de Otavalo, y de Soledad Varea sobre las voces de los adolescentes acerca del cuerpo maternal y la resistencia. La relevancia de la problemática radica en el uso de las historias de vida y el rastreo de la participación de la mujer en diversos aspectos de la política y cultura. Cierra esta obra la sistematización del trabajo de los talleres (p.365-387).

En suma, la obra, a pesar de ser demasiado ecléctica y dispersa, es un esfuerzo por dar cuenta de la implementación de la interculturalidad por la cooperación internacional para cambiar los sistemas de salud andinos. Llama la atención que esta obra, producida y publicada en Ecuador, no haya contado con el aporte de la Universidad Andina Simón Bolívar (Quito). Allí funciona un exitoso Programa de Doctorado en Estudios Culturales, el cual ha publicado abundante bibliografía sobre la interculturalidad, recuperando estratégicamente los aportes de la escuela de los estudios de la sub-alternidad de la India y de múltiples vertientes latinoamericanas de reflexión crítica sobre la colonización y la descolonización. Esta ausencia es aún más notoria, porque desde ese espacio académico son los indígenas, los ecuatorianos y los afro-descendientes quienes han asumido una reflexión sobre la realidad de su país. Téngase en cuenta que en Ecuador, la interculturalidad ha surgido "desde abajo", reflexionando intensamente acerca del concepto andino de "el Buen Vivir" en numerosas publicaciones, todas ellas ignoradas en la bibliografía de la obra reseñada. Y llamo la atención sobre esto, porque fue desde esa Universidad que se ha visibilizado el funcionamiento del multiculturalismo neoliberal y nada menos que un mecanismo encubridor por excelencia de las nuevas formas de colonización que se implementa gracias a la interculturalidad funcional, cuyos dispositivos de poder permiten la permanencia y fortalecimiento de las estructuras sociales establecidas con una matriz colonial (Walsh, 2009). Por ejemplo, como lo menciona la obra incidentalmente, el sistema de salud boliviano intercultural no asume la necesidad de que los médicos tradicionales incorporados en los hospitales gocen de derechos laborales y salarios. Muchos biomédicos todavía quieren que los pagos sean en especies (huevos, 
gallinas o cerdos), pero de ningún modo en salario digno. Este tema de inequidad salarial y de injusticia ha movilizado, desde el 2006 hasta la fecha, a las instituciones no oficiales de la medicina tradicional sin conseguir mayores avances.

La interculturalidad en salud en Bolivia fue impuesta "desde arriba" y tiene un desarrollo independiente, de tal suerte que no compartimos el punto de vista del editor. Él asume una continuidad histórica entre las "iniciativas" interculturales actuales y las supuestas acciones de los terapeutas tradicionales y sus organizaciones por establecer un acercamiento con el sistema biomédico para el reconocimiento que estaba en poder de estos últimos (p.24). Subrayamos que no sólo se trata de procesos históricos totalmente distintos temporalmente, sino que responden a proyectos conceptualmente diferentes. Los terapeutas tradicionales entre 1960 hasta 2005 actuaban en pleno proceso de despenalización de su práctica, mientras que hoy en día se apoyan en el respaldo constitucional. A pesar de ello, el discurso del fortalecimiento de la medicina tradicional por el Estado no deja de ser un mero enunciado, pues en la práctica se toman medidas que van en sentido contrario. Por ejemplo, en Bolivia, gracias a las compensaciones monetarias condicionadas (Bono Madre Niño-Niña Juana Azurduy de Padilla) se restringe a las parteras tradicionales a ejercer su práctica porque se cuestiona su calificación; ellas no pueden competir con los biomédicos asegurando el certificado de nacimiento del recién nacido, menos compensar a la madre con un monto de dinero desde el embarazo hasta el parto y desde el nacimiento del bebé hasta que cumpla 2 años. Lo paradójico es que a pesar de estas medidas, la mortalidad materna en Bolivia no ha descendido (Prieto, Cid, 2010; Bolivia, 2008).

Apoyada en documentación histórica, aclaro que las dirigencias de la Sociedad Boliviana de Medicina Tradicional (SOBOMETRA) en ningún momento "menospreciaban su propio patrimonio" ceremonial (p.40), tal como lo afirma el editor. Esta antigua institución trabajó incansablemente por la defensa de numerosos sitios sagrados de curación en el altiplano y ciudades de La Paz cuando existía penalidad. Muchos espacios ceremoniales estaban prohibidos para los terapeutas tradicionales hasta 1978, pero SOBOMETRA y sus dirigentes los ocuparon. Basta mencionar las primeras ceremonias del solsticio de invierno en el área arqueológica de Tiwanaku bajo control policial (1978), las ceremonias públicas de Huaraku (1984) y Corazón de Jesús (1985), entre otras muchas celebradas en diversos sitios emblemáticos de La Paz. Las garantías escritas de lo afirmado se encuentran en la correspondencia recibida por el Ministerio de Previsión Social y Salud Pública, la Prefectura de La Paz y la Alcaldía de La Paz, pero, sobre todo, sustento mi afirmación en el archivo fotográfico privado del presidente vitalicio de SOBOMETRA, Walter Álvarez Quispe.

Si se continúa disociando teoría y práctica intercultural desde los Estados se producirá un efecto contrario al perseguido: reducir las inequidades y potenciar una salud de calidad para todos los ciudadanos en igualdad de condiciones. Por el momento, todo parece indicar que la asimetría entre biomedicina y medicina tradicional está siendo exacerbada en la implementación de medidas que crean contrasentidos en la subregión andina. 


\section{REFERENCIAS}

PRIETO, Lorena; CID, Camilo.

Análisis del sector salud Bolivia. S.1.: Banco

WALSH, Catherine.

Interamericano de Desarrollo. 2010.

Interculturalidad, estado, sociedad, luchas (de)

BOLIVIA.

coloniales de nuestra época. Quito: Universidad Andina Simón Bolívar. 2009.

Instituto Nacional de Estadística, Ministerio de Salud y Deportes. Encuesta nacional de demografía y salud 2008. La Paz: Instituto Nacional de

Estadística; Ministerio de Salud y Deportes. 2008.

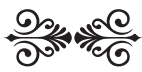

